\title{
A New Design of Dual-Axis Solar Tracking System with LDR sensors by Using the Wheatstone Bridge Circuit
}

\author{
First A. Author, Mahdi saeedi, Second B. Author, Reza Effatnejad*
}

\begin{abstract}
Nowadays, using photovoltaic (PV) cells is among the power generation methods that absorb solar energy and convert it into electrical energy. The sun moves from east to west during the day and its radiation angle changes relative to the Earth in different seasons. So, the output power of PV panels changes as well. The output power of PV panels increases by being located in a position perpendicular to the angle of the sun's rays. This study aims to design and implement a dual-axis solar tracker (DAST) to increase the output power of the PV panel. This simple system has high efficiency and adjusts the PV panel based on solar radiation by moving simultaneously on two axes. An analog controller is used for its control system. DAST control system is a closed-loop system that uses Wheatstone bridge circuit function along with light-dependent resistors (LDRs). A small DAST was designed and built to validate the proposed system, the performance of which was verified. Based on the experiments, I-V and P-V specifications were obtained. Finally, it was found that the output power of the PV panel using solar tracker was higher than that of the fixed panel.
\end{abstract}

Index Terms - Wheatstone bridge, LDR sensors, DAST system, $P V$ panel, closed-loop system.

\section{INTRODUCTION}

$\mathrm{T}$ he most efficient and fastest solar energy absorption technology is the photovoltaic converter. solar cells convert direct sunlight to direct current through the photovoltaic effect. To maximize the output power of PV panels during the day, they must be kept in the position perpendicular to solar radiation is needed [1].

The geographical location and situation of the sun are constantly changing. The output power of the PV panel depends on the amount and angle of solar radiation, the type and number of cells, the temperature of the cell loads, and the voltage (or battery). In general, fixed solar panels do not receive maximum amounts of solar energy continuously [2, 3]. To solve this problem the solar tracking (ST) can be used to maximize the output power of the PV panel. The solar tracker receives maximum amount of solar radiation during the day by

M. S. Author, Department of Electrical Engineering, Islamic Azad University, Karaj Branch, Alborz, Iran (e-mail: mahdi.saeedi31@yahoo.com).

*R. E. Corresponding Author, Department of Electrical Engineering, Islamic Azad University, Karaj Branch , Alborz, Iran (e-mail: reza.efatnejad@kiau.ac.ir). positioning the PV panel perpendicular to the sun's rays [4]. Various methods have been widely used to track the sun's rays. In general, they can be classified in two ways:

1) types of open-loop tracking based on solar movement.

2) types of closed-loop tracking using sensor-based controllers.

In an open-loop system, solar tracking methods are modeled through mathematical models, so that the control algorithm or AI tool is used to get the maximum power tracking point $[5,6]$. The fuzzy logic controller (FLC) is also an open-loop tracking method. The fuzzy logic control is designed as software to decide the time of the ST system. As a result, the closest position to receive direct sunlight is obtained from the database $[7,8]$.

In a closed-loop system, a variety of active sensors such as LDR are used to detect the sun's position [9-11]. Many solar tracker systems have been reported in the literature and they differ according to employed tracking methods, such as sensors-based tracker method, geometric and astronomical equations-based method, artificial intelligent based method, etc. Sensors-based solar trackers are the most proposed systems in the literature due to their simplicity and efficiency/price ratio. Sensor-based solar trackers widely use light sensors such as photoresistors (LDRs), photodiodes, solar cells, pyrometers...to follow instantaneously sun's movement. The most commonly used sensors are LDRs in view of their simple circuit and very low price. For these reasons, many researchers have used this type of sensor in their systems.

The ST system is both single-axis and two-axis. Using a single-axis structure, the ST system follows the sun in the sky from east to west [12]. The ST system with a double-axis structure has higher accuracy and follows the elevation angle of the sun [13-15]. This study proposes a DAST based on LDRs, which simultaneously adjusts the PV panel relative to solar radiation on two axes. In the solar tracking system, a simple design of DAST is provided by the Wheatstone bridge circuit 
along with LDRs. Using a Wheatstone bridge circuit, an output of the sensitive parameter function is obtained by a resistance sensor. To achieve higher sensitivity, the Walton bridge circuit is used to measure two elements compared to each other [16, 17].

Results of experiments have demonstrated the feasibility of the DAST system. The remainder of the paper is organized as follows: Section 2 describes the structure of the DAST system in terms of physical design and control circuit. The controlling method of the DAST system is proposed in Section 3. In Section 4, a scaled-down prototype of DAST system is built and tested. The main conclusions of this article are drawn in Section 5.

\section{SOLAR TRACKING SYSTEM}

\section{A. Mechanical Design}

The increasing growth of the market of photovoltaic systems has led to an increasing interest in ST systems. The design of the structure of ST systems is important in terms of

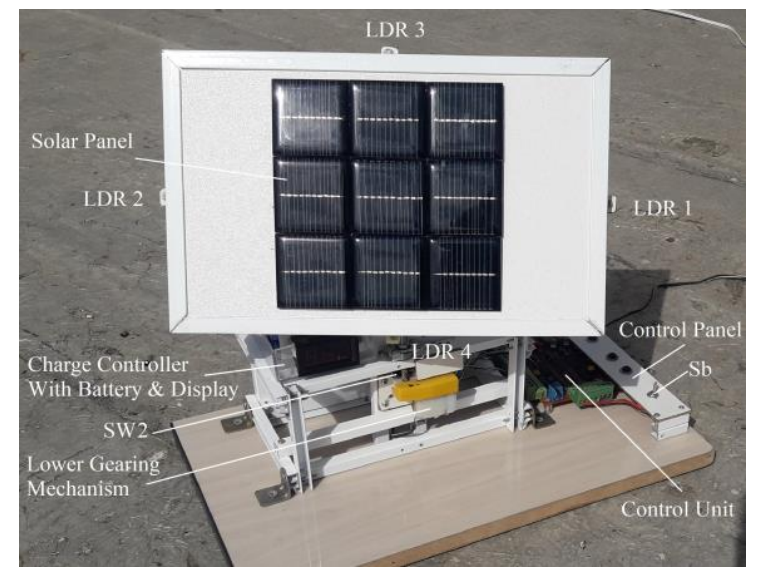

(a)

Fig. 1. (a) and (b) The DAST structural design.

\section{1) Static part}

The static part of the DAST system includes a base frame structure, lower gearing mechanism, control panel, control unit, charge controller and battery, vertical shaft, ball bearings, and micro switches (SWs). The base frame structure keeps all parts of the DAST system fixed and secured on the ground. The arms are considered in different directions to support the DAST system against wind forces, and all joints are integrally connected. The lower gearing mechanism (DC motor with gear mechanisms) is connected to the vertical shaft to bear the axle load along with the gear mechanisms (buck converter) situated in a suitable box on the structure (Fig. 2). The control unit handles the controlling task and coordinates all parts of the DAST system and also the PV panel's movement in all directions. The control panel is intended to change the manual and automatic control of the DAST system. The charge controller is a device used to manage the energy flow in DAST systems. The work of it including overcharge protection, deep discharge protection, system power management. Battery is a device used for storing solar charge in solar systems. The main performance, strength, and cost. In this paper, the aim is to control the ST system in all directions (East-West-North-South) to keep the PV panel perpendicular to the sun's rays. The DAST system is designed and built in a scaled-down laboratory prototype. The design of this DAST system in larger dimensions (e.g. $10 \mathrm{x}$ ) can be used to support single or multiple PV panels on a structure. The mechanical structure of the tracker should be flexible to support the weight of the panel, frame, actuators, shafts, gear mechanisms, and solar measurement devices $[18,19]$.

In addition, the flow of destructive forces (wind power) can affect the structure of the DAST system. Therefore, wind power is considered important in designing the system. The proposed system is suitable for low wind speed (about $20 \mathrm{~m} / \mathrm{s}$ ). If a larger tracker system is designed and a stronger driving system (electric jacks) used, it will be more resistant to stronger winds. To this end, the arms are considered in different directions to withstand wind force. The design of the DAST system is shown in Fig. 1 which consists of two fixed and moving parts [20-22].

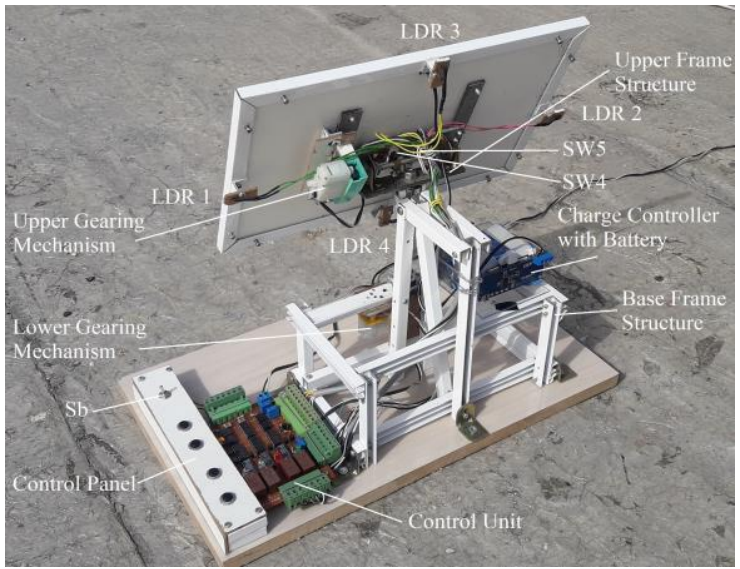

(b)

axis of the horizontal rotation of the PV panel (vertical shaft) allows the rotation of the PV panel to track the angle of the solar radiation from the east to the west. The ball bearings facilitate the rotation of the PV panel on the structure.

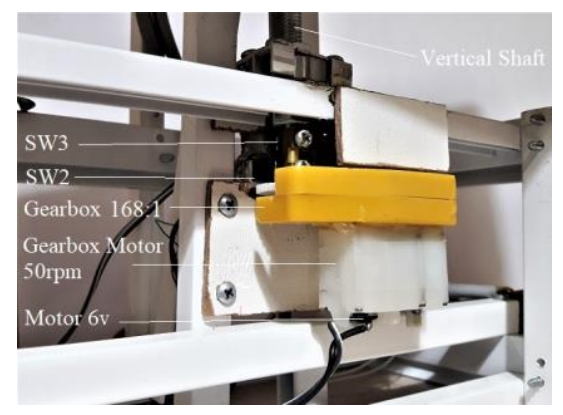

Fig. 2. The lower gearing mechanism

To limit the horizontal movement of the PV panel, three micro switches are placed in the horizontal actuator control circuit next to the vertical shaft; two of which are SW2 and SW3 
situated at the beginning and the end of the rotary motion of the PV panel and the SW1 micro-switch switches it off at night when the PV panel rotates to its original position in the early hours of the day.

\section{2) Moving part}

The moving part is connected to the end of the upper part of the vertical shaft and includes the PV panel, upper gearing mechanism, the horizontal shaft, the PV panel holder, the sunlight measurement system (LDRs), and the micro switches. PV panels generate electric power using solar cell modules. The vertical rotational axis of the PV panel (horizontal shaft) allows the PV panel to rotate in order to track the angle of the solar radiation from the north to the south. The upper gearing mechanism (DC motor with gear mechanisms) is connected to the horizontal shaft to bear the axle load along with the gear mechanisms situated in a suitable box on the moving part. The PV holder holds it on the shaft (Fig. 3). The LDRs are located in the four directions around the PV panel to measure sunlight [23-25]. Both SW4 and SW5 micro switches are situated in the vertical actuator control circuit next to the horizontal shaft on the moving part which is placed at the beginning and the end of the rotary motion of the PV panel (north-south).

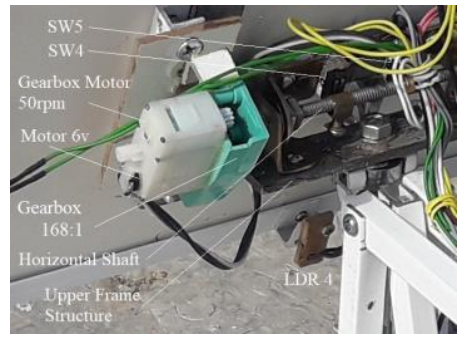

Fig. 3. The upper gearing mechanism

\section{B. Electronic Design}

The DAST system operates in both manual and automatic forms using the control panel placed on the chassis. If the 3status key (high - middle - low) is set to high, the DAST system function is automatically performed by the control circuit and LDR sensors. If it is set in the middle position, the system has no function. Setting the Sb key in the middle position means that the system is manually operated, and each push button is responsible for the movement of the DAST system in one of the four directions (Fig. 1 (b)).

The control of the proposed DAST system is carried out by ICs circuits and transistors. To track the angle of the sun's radiation, it is necessary to determine the position of the sun, and this requires an LDR light detection sensor. LDR resistance decreases as the light intensity increases. Since one sensor is not enough to track the position of the sun, four LDRs in the four directions of the PV panel are used to calibrate the tracker system (Fig. 1 (a)).

\section{CONTROL METHOD}

The designed DAST system is a developed closed-loop system in whose op-amps an output of the sensitive parameter function is obtained by a resistance sensor LDR using the
Wheatstone bridge circuit.

\section{A. The Wheatstone Bridge}

The Wheatstone bridge was first used to measure very low values of resistance. It is more precise compared to many other techniques and simply operates by dividing the voltage. One of the most important and well-known applications of the Wheatstone bridge circuit is measuring the variations of the sensor resistance [16, 17].

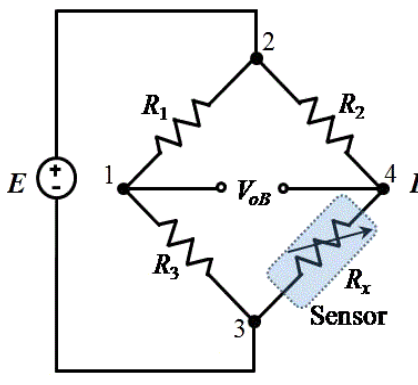

(a)

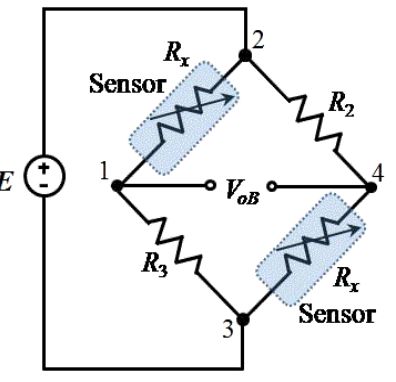

(b)
Fig. 4. The structure of the Wheatstone bridge. (a) full bridge; (b) half bridge.

Fig. 4 (a) it is fully illustrated how to connect and use the resistance sensor in the quadratic Wheatstone bridge circuit. The half-bridge structure shown in Fig. 4 (b) is used to measure two elements with the same type to achieve higher sensitivity. This method is used to provide a signal in the output of resistance sensors such as light-dependent resistance sensors and LDRs and so on $[26,27]$. The resistance $R_{x}$ of a linear resistance sensor can be as follows:

$$
R_{x}=R_{0}(1 \pm k x)
$$

Where $k$ is the conversion constant of the sensor, $x$ depends on the measured quantity, and $R_{0}$ is the nominal resistance of sensor element $(x=0)$. When the resistance in other parts of the bridge is equal to $R_{0}$, the output bridge $V_{o B}$ is equal to [26]:

$$
V_{o B}=\frac{E \cdot k x}{k_{B}\left(1+\frac{k x}{2}\right)}
$$

In Equation (2), $E$ is the voltage of the power supply of the bridge, and $k_{B}$ is the bridge constant (full bridge $k_{B}=4$ and a half bridge $k_{B}=2$ ). Equation (2) clearly shows that the output voltage of the bridge $V_{o B}$ will be the nonlinear function. Since the percentage of change in the resistance element is very low ( $k x \ll 1$ ), the nonlinearity is also low. In contrast, as it increases, it's $k x$ also increases. Nonlinearity with respect to the operating range can be increased up to $\% 8$. Given these points, it provides the advantage of a bridge-based measure [26]. 


\section{B. Solar Tracking Control System Design}

In the closed-loop DAST system, the intensity of the sunlight is considered as a reference input signal (Fig. 5). For solar tracking, the position of the sun needs to be detected by optical sensors. The proposed tracking system uses optical sensors to adjust the PV panel based on the angle of the sun. LDR sensors have variable electrical resistance depending on the light intensity and their resistance decreases with increasing light intensity. In there is an imbalance in the voltages generated in the Wheatstone bridge branches by the LDR sensor, a voltage difference is created due to the difference between the angle of the solar radiation and the position of the PV panel (Fig. 4 (b)).
Then, the voltage generated at the output of the Wheatstone bridge is transmitted to the op-amps and amplified as well. The output voltage of the op-amps by the control circuits activates the relay. The relay rotates the engine of the tracking system in the desired direction, and the PV panel will rotate around its axis so that the ST system automatically places the PV panel perpendicular to the direction of the sun rays. Accordingly, the control system continuously monitors the solar radiation angle and PV panel by LDRs and sends a differential control signal to the relay of the tracker motor until the voltage difference in the bridge branches becomes less than a threshold value [8].

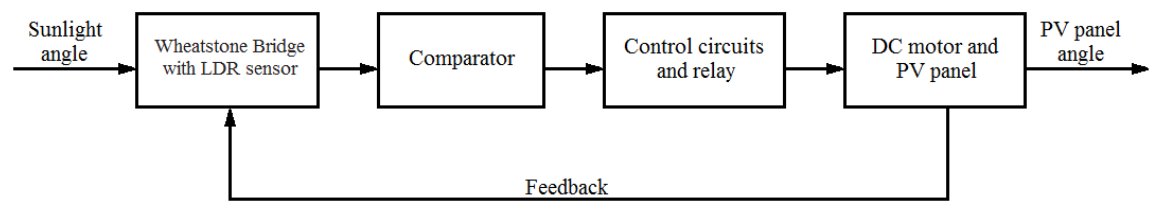

Fig. 5. Block diagram of the DAST system.

In many DAST systems, a comparator with four-quadrant LDR has been used to determine the position of the sun $[13,14]$. However, in This paper, the LDR sensors are placed on the four sides of the PV panel at a distance of $1 \mathrm{~cm}$ from the panel surface (Fig. 1 (b)) so that when the angle of the sun changes, the LDR sensor remains in the shadow. Also, the proposed DAST system is more sensitive and faster due to the use of the Wheatstone bridge circuit. Sensors LDR1 and LDR2 are used to calibrate the PV panel relative to the horizontal axis and sensors LDR3 and LDR4 are employed to calibrate the PV panel relative to the vertical axis.

The DAST system has two circuits for controlling the rotary motion of the PV panel in both horizontal and vertical axes and each axis operates in two directions. Each hardware circuit consists of three parts including a Wheatstone bridge with an LDR sensor, op-amps, and control circuits. To achieve maximum power for the PV panel, the astronomical tracking processes proceed simultaneously to make the PV panel perpendicular to sunlight. Fig. 6 is a hardware circuit for DAST system.

\section{1) Hardware Circuit of Horizontal Motion Control}

The DAST moves automatically upon a change in the sun's radiation. The horizontal control hardware circuit is used to control the rotary motion of the PV panel in the east (E) and west (W) (Fig. 6). The Wheatstone bridge (horizontal rotational axis) includes R2 to R6 resistors along with optical sensors LDR1 and LDR2. The intensity of the sunlight is measured by the LDR sensor circuit. If there is an imbalance in the voltages generated in the bridge branches by LDR sensors, the VE and $\mathrm{VW}$ voltages are considered as the generated voltages in the east and west, respectively. Then, the voltage generated in the bridge output is transmitted to the UE and UW op-amps. The op-amps output voltage is controlled by ICs control circuits and transistors which activates the RE and RW relays, and LEDs, DE and DW turn on and confirm their activation. Relays rotate the M EW tracker engine in the desired direction, and the PV panel will rotate around its axis to place the PV panel perpendicular to the direction of the sun rays. At this time, due to the uniform and even solar radiation to the LDRs, the PV panel stops at its position (Fig. 7). To prevent the PV panel from

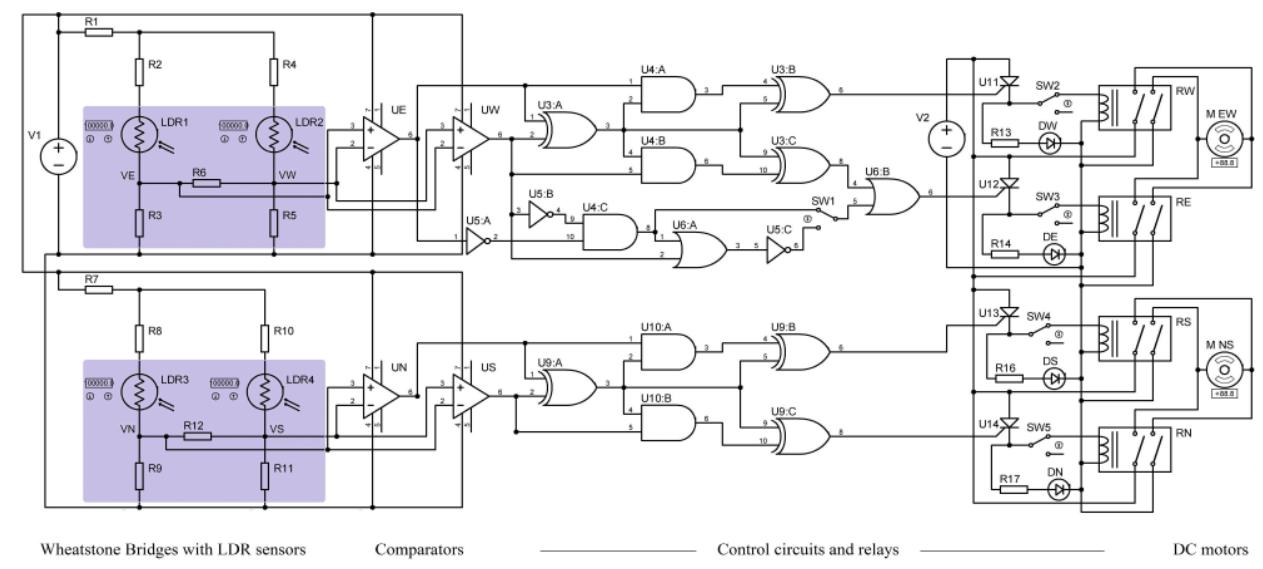

Fig. 6. The control circuit of the DAST system. 
falling out of the range, at the end of the route, the SW2 and SW3 micro switches are located in both directions of east and west, respectively.

At night when it is dark, a controlled route for the PV panel is considered to return it back to its initial state as the sun rises (sun radiation from the east). The PV panel starts to move eastward and places it at the initial state in the early hours of the day by reaching the end of the route and hitting with the microswitch SW1 (Fig. 7).

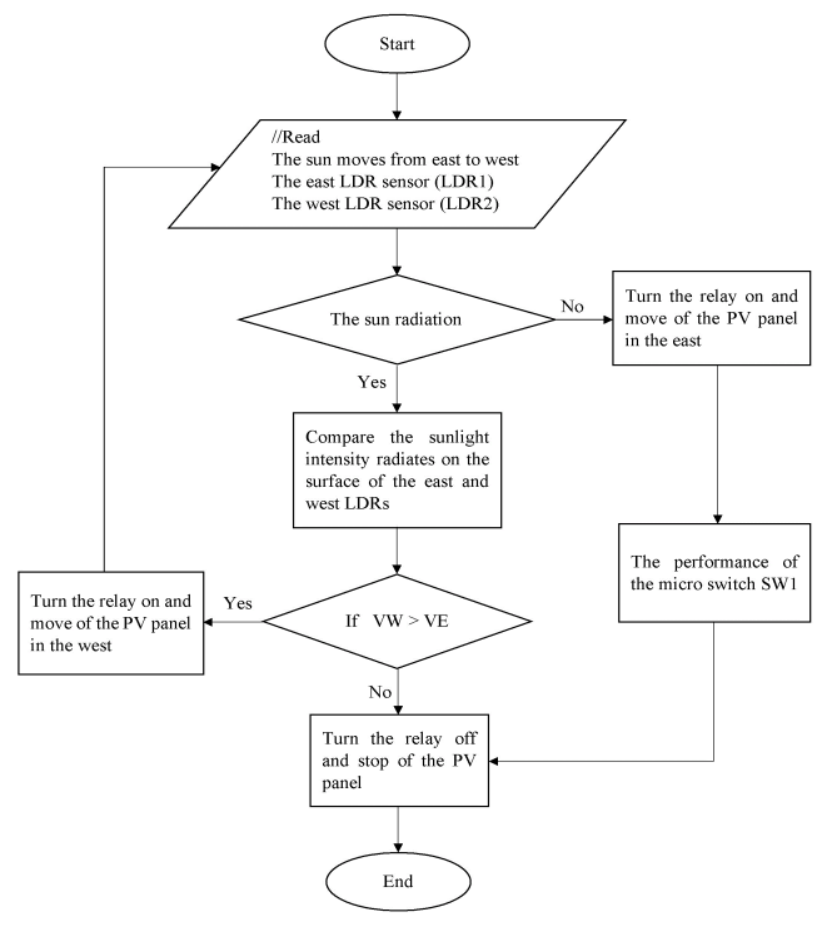

Fig. 7. Working Flowchart of DAST system for Horizontal Motion.

\section{2) Hardware Circuit of Vertical Motion Control}

The vertical control hardware circuit is used to control the rotary motion of the PV panel in the north $(\mathrm{N})$ and south $(\mathrm{S})$ (Fig. 6). The Wheatstone bridge (vertical rotational axis) includes R8 to R11 resistors along with optical sensors LDR3 and LDR4. The intensity of the sunlight is measured by the LDR sensor circuit. If there is an imbalance in the voltages generated in the bridge branches by LDR sensors, the VN and VS voltages are considered as the generated voltages in the north and south, respectively. Then, the voltage generated in the bridge output is transmitted to the UN and US op-amps. The op-amps output voltage is controlled by ICs control circuits and transistors which activates the RN and RS relays. Next, LEDs, DN, and DS turn on and confirm their activation. Relays rotate the M NS tracker engine in the desired direction, and the PV panel rotates around its axis to place the PV panel perpendicular to the direction of the sun rays. At that time, due to the uniform and even solar radiation to the LDRs, the PV panel stops at its position (Fig. 8).To prevent the PV panel from falling out of the range, at the end of the route, the SW2 and SW3 micro switches are located in both directions of north and south, respectively.

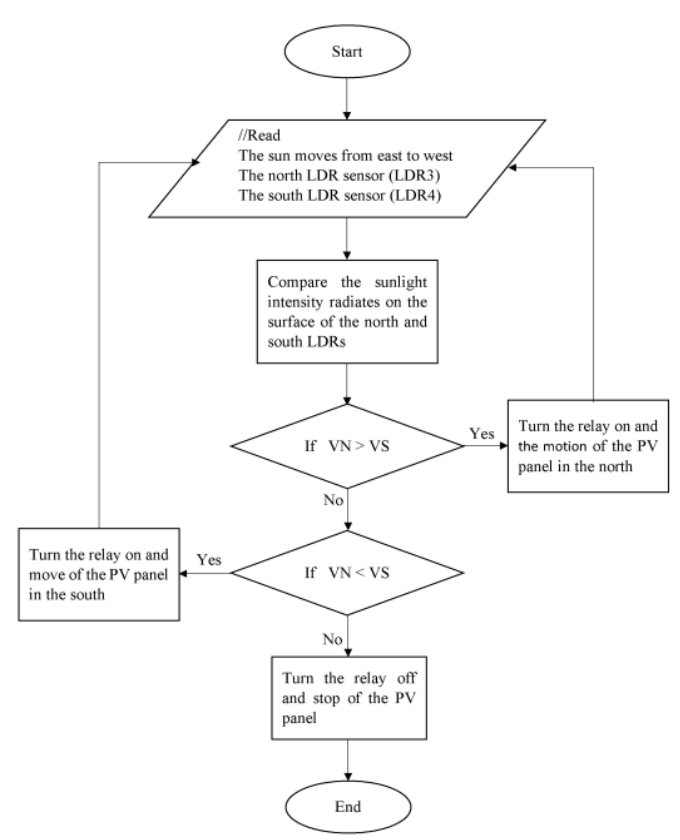

Fig. 8. Working Flowchart of DAST system for Vertical Motion.

\section{System TESTING AND RESUlTS}

\section{A. Performance of the DAST system}

To investigate the performance of the DAST system and demonstrate its automatic control, a laboratory sample was made and tested. The operation was conducted on 4 June 2020, in Karaj, Iran. The latitude and longitude coordinates for Karaj, Iran is $35.5^{\circ}$ North and $51^{\circ}$ East, respectively. At this time, the angle of radiation is about $73^{\circ}$. To maximize power, the PV panel should be placed perpendicular to the sun radiation angle. In Fig. 9, the PV panel is positioned at different angles depending on the angle of solar radiation.

Results of the measurement of voltages created for the DAST systems on a sunny day are given in Table 1 , and $R_{L D R}$ is the resistance of the LDR (Fig. 9, Eq. 2). The intensity of solar radiation is about 100,000 lux in direct sunlight and 65,000 lux in the shade, respectively.

The sun moves from east to west during the day $[2,3]$. By the movement of the sun, the DAST system simultaneously moves in all directions and locates the PV panel in the direction

of solar radiation. The performance of the DAST system is examined in four modes as follows:

1. The motion of the panels to the west

2. The motion of the PV Panel to the north

3 . The motion of the panels to the south

4. The motion of the panels to the east

As the sun radiates on the surface of the light sensors, their ohmic resistance decreases. The higher the radiation intensity, the lower the sensor resistance $[16,17]$. As the sun radiates on the surface of the sensors (LDRs) in different modes of the DAST system, their ohmic resistance changes (Table 1).

In the first mode, as the sun moves towards the west (Fig.9 (a)), the angle of solar radiation on the surface of the PV panel 
TABLE I

FUNCTIONS OF CONTROL SYSTEM

\begin{tabular}{|c|l|c|c|c|c|c|c|c|c|c|}
\hline NO & \multicolumn{1}{|c|}{ Function Test } & $\begin{array}{c}R_{L D R 1} \\
(\mathrm{k} \Omega)\end{array}$ & $\begin{array}{c}R_{L D R 2} \\
(\mathrm{k} \Omega)\end{array}$ & $\begin{array}{c}R_{L D R 3} \\
(\mathrm{k} \Omega)\end{array}$ & $\begin{array}{c}R_{L D R 4} \\
(\mathrm{k} \Omega)\end{array}$ & $\begin{array}{c}\mathrm{VE} \\
(\mathrm{V})\end{array}$ & $\begin{array}{c}\mathrm{VW} \\
(\mathrm{V})\end{array}$ & $\begin{array}{c}\mathrm{VN} \\
(\mathrm{V})\end{array}$ & $\begin{array}{c}\mathrm{VS} \\
(\mathrm{V})\end{array}$ & LED \\
\hline 1 & $\begin{array}{l}\text { The motion of the PV panel to the } \\
\text { west }\left(R_{L D R 1} \succ R_{L D R 2}\right)\end{array}$ & 0.128 & 0.121 & - & - & 4.40 & 4.74 & - & - & Green \\
\hline 2 & $\begin{array}{l}\text { The motion of the PV panel to the } \\
\text { north }\left(R_{L D R 3} \prec R_{L D R 4}\right) .\end{array}$ & - & - & 0.111 & 0.114 & - & - & 5.54 & 5.24 & Blue \\
\hline 3 & $\begin{array}{l}\text { The motion of the PV panel to the } \\
\text { south }\left(R_{L D R 3} \succ R_{L D R}\right) .\end{array}$ & - & - & 0.105 & 0.102 & - & - & 5.94 & 6.08 & Yellow \\
\hline 4 & $\begin{array}{l}\text { The lack of sun radiation to the LDR1 } \\
\text { and LDR2. }\end{array}$ & 5.34 & 5.39 & - & - & 1.64 & 1.66 & - & - & Red \\
\hline 5 & $\begin{array}{l}\text { The lack of movement of the PV panel } \\
\left(R_{L D R 1}=R_{L D R 2}\right) .\end{array}$ & 0.096 & 0.096 & - & - & 6.57 & 6.57 & - & - & - \\
\hline 6 & $\begin{array}{l}\text { The lack of movement of the PV panel } \\
\left(R_{L D R 3}=R_{L D R 4}\right) .\end{array}$ & - & - & 0.098 & 0.099 & - & - & 6.38 & 6.38 & - \\
\hline
\end{tabular}

changes. As a result, the LDR1 is gradually placed in the shade and its ohmic resistance increases. According to Fig. 6, due to the increase in the ohmic resistance of the LDR1, the VW and VE voltages are out of balance at the Wheatstone bridge and the VW voltage is higher than the VE voltage (Table 1). As a result, the PV panel starts moving in the west direction, and when the VW and VE voltages equalize, the PV panel stops. In Fig. 9 (a), the PV panel is not perpendicular to the solar radiation. As the Radiation to the surface of LDR1 and LDR2 sensors is not uniform $(\mathrm{VE}<\mathrm{VW})$, the green LED is on and the PV panel rotates westward. in Fig. 9 (b), after the movement of the PV panel, the DAST system stops when it stands perpendicular to the solar radiation angle $(\mathrm{VW}=\mathrm{VE})$.

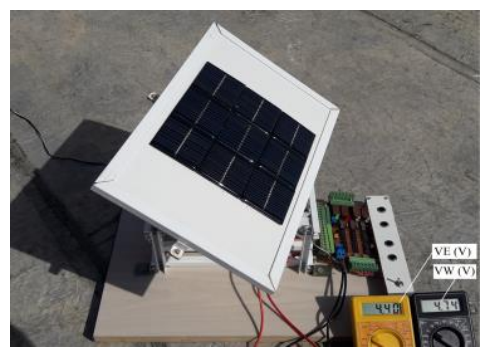

(a)

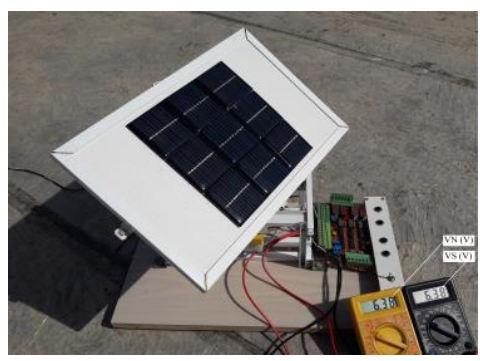

(c)
In the second mode, in the early hours of the day, as the sun moves towards the west, the angle at which the solar radiation reaches the earth gradually increases. Like the first mode, the angle of solar radiation on the surface of the PV panel changes, so the LDR4 is gradually placed in the shade and its ohmic resistance increases. According to Fig. 6, due to the increase in the ohmic resistance of the LDR4, the VN and VS voltages are out of balance at the Wheatstone bridge and the VN voltage is higher than the VS voltage (Table 1). As a result, the PV panel starts moving in the north direction, and when the VN and VS voltages equalize, the PV panel stops. In Fig. 9 (c) After the movement of the PV panel to the west, the DAST system stops when it stands perpendicular to the solar radiation angle $(\mathrm{VN}=\mathrm{VS})$.

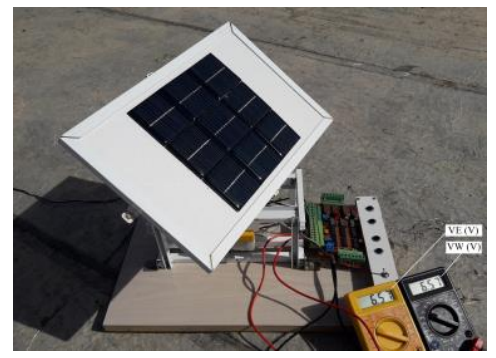

(b)

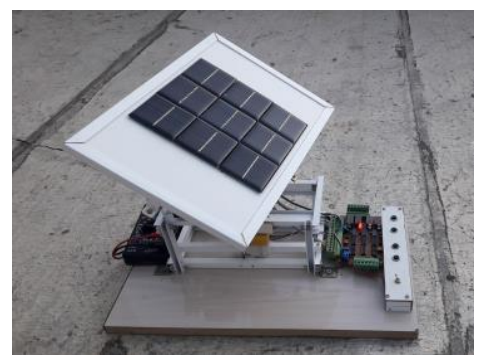

(d)

Fig. 9. Performance of DAST system. (d) At 09:30 a.m., The motion of the PV panel in the west due to the lack of uniform sun radiation to the LDR1 and LDR2; (c) At 09:30 a.m., The lack of movement of the PV panel due to the uniform sun radiation to the LDR1 and LDR2; (b) At 09:30 a.m., The lack of movement of the PV panel due to the uniform sun radiation to the LDR3 and LDR4; (a) At 05:30 a.m., The motion of the PV panel in the east due to the lack of sun radiation to the LDR1 and LDR2. 
In the third mode, as the sun moves westward in the afternoon, the angle at which the solar radiation reaches the earth gradually decreases. Due to the changes in the angle of solar radiation, the LDR3 is slightly placed in the shade and its ohmic resistance increases. According to Fig. 6, due to the increase in the ohmic resistance of the LDR3, the VN and VS voltages are out of balance at the Wheatstone bridge and the VS voltage value is higher than $\mathrm{VN}$ voltage (Table 1). As a result, the PV panel starts moving in the south direction, and when the VN and VS voltages equalize, the PV panel stops (Fig.9 (C)).

In the fourth mode, after sunset and when there is no solar radiation, the ohmic resistance of the LDR1 and LDR2 increases sharply. As a result, VE and VW voltages decrease (Table 1). The DAST system then moves the PV panel to the east and places it in the position of the beginning of the day. In Fig. 9 (d), since there is no radiation on the surface of LDR1 and LDR2 sensors, the red LED is on and the PV panel rotates eastward and stops.

\section{B. I-V and P-V characteristics}

The power output of the PV panel depends on the type of cells and the number of the cells in the PV panel, the amount and angle of solar radiation, the temperature of cell and voltage loads (or battery).

$\mathrm{I}-\mathrm{V}$ and P-V characteristics of PV panel are shown in Fig.10, 11. In this proposed system configuration we have selected the 9 number of cells are connected in parallel. The maximum power by PV panel with respect to the Solar Irradiation at temperature of $32^{\circ} \mathrm{C}$ is $1.28 \mathrm{Wp}$ (volts $\times$ amps $=$ power, so $4.1 \mathrm{~V}$ $\times 0.312 \mathrm{~A}=1.279 \mathrm{~W})[20,28]$.

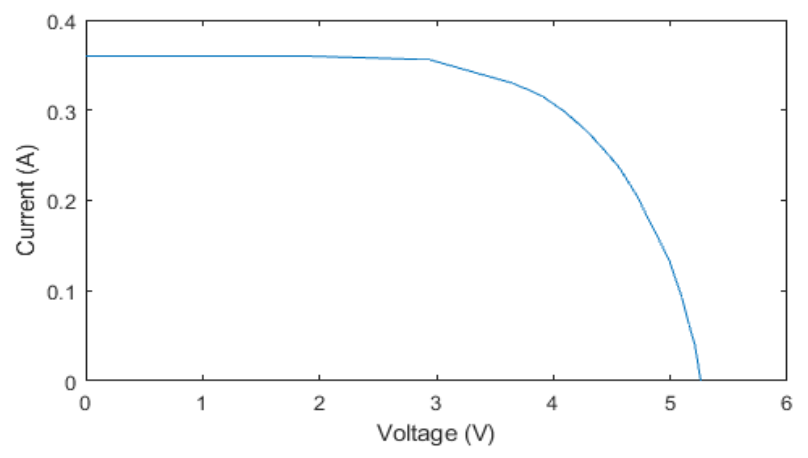

Fig. 10. I-V Characteristics of PV panel.

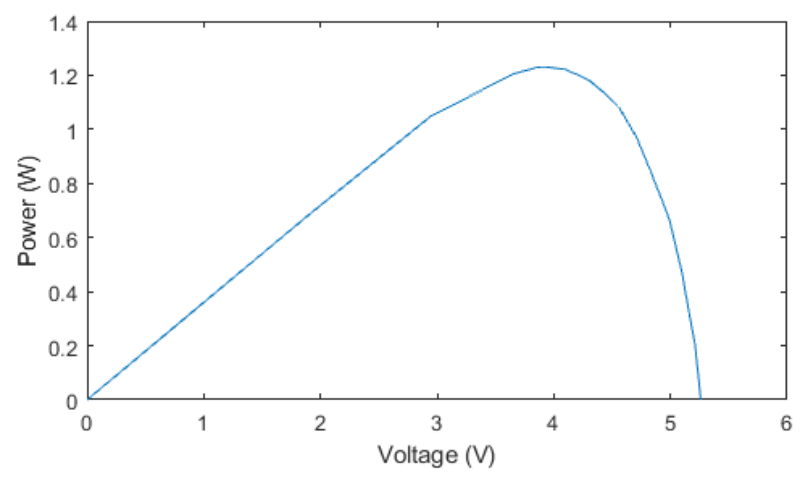

Fig. 11. P-V Characteristics of PV panel.

\section{Output power of the PV panel}

Fig.12 shows that the output power of the PV panel is measured simultaneously in both modes of fixed solar panel and solar tracker during the day. Measurements are made every 30 minutes from 7:00 a.m. to 19:00 p.m. In the first mode, the PV panel is fixed to the south direction during the day and the sun radiates on the earth's surface at an angle of $73^{\circ}$. At 1:00 p.m., the PV panel is placed perpendicular to the angle of the sun's rays, so its output power reaches its maximum value. In the morning and evening, due to the fact that the PV panel is not at the optimum angle, the amount of its output power decreases, and as a result, it loses a significant amount of energy during the day.

In the second mode, the PV panel is moved by the DAST system and adapts to the angle of the sun's radiation at any given moment to be in the same direction. In this mode, it can be observed that at any time of the day when the angle of the sun changes and the intensity of the sun's radiation increases, the PV panel is moved by the DAST system and is optimally positioned. At this point, the output power of the PV panel reaches its peak value and remains constant for a long time. Maximum generated Energy is about $6.14 \mathrm{Wh} / \mathrm{Wp}$ for fixed and about $9.10 \mathrm{Wh} / \mathrm{Wp}$ for DAST system. The results reveal that the efficiency gain of the DAST is $48.2 \%$ higher than that of the fixed panel $[2,25]$.

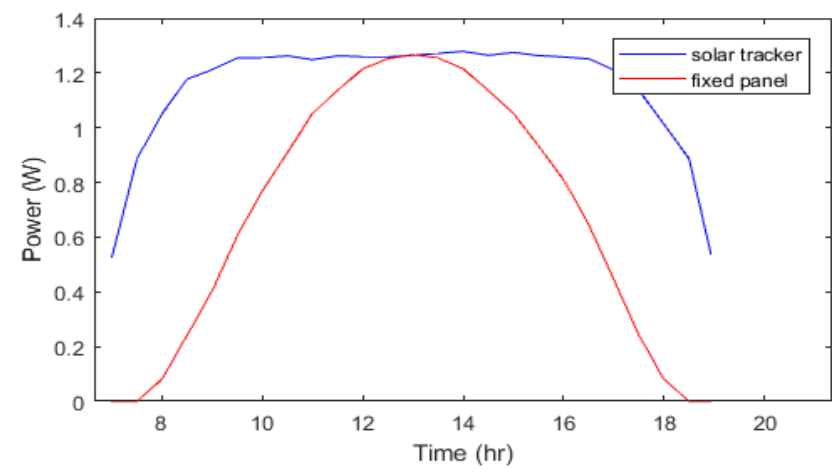

Fig. 12. Output power of fixed panel and solar tracker.

\section{CONCLUSION}

The solar tracking system detects the astronomical position of the sun during the day and increases the output power of the PV panel by placing it in a suitable position relative to the angle of the sun's rays. Many solar tracking systems have been developed so far that either have not been able to move on two axes or have been based on geometric and astronomical equations and artificial intelligence, which are expensive. This study presented a new DAST based on LDRs, which adjusts the PV panel relative to the angle of the sun's rays by moving simultaneously on two axes. DAST is a very simple and costeffective control system that utilizes Wheatstone bridge circuit function and LDRs. If this controller is used, it is possible to control PV panels on the metal structure both individually and in an integrated manner. Therefore, the experimental findings of this solar tracking system can help develop solar energy applications. 


\section{REFERENCES}

[1] G. K. Singh, "Solar power generation by PV (photovoltaic) technology: A review," Energy, vol. 53. Elsevier Ltd, pp. 1-13, 01-May-2013.

[2] Mark Hankins, Stand-alone Solar Electric Systems: The Earthscan Expert Handbook for Planning, Design and Installation. Earthscan, 2010.

[3] S. N. Geoff Stapleton, Grid-connected Solar Electric Systems: The Earthscan Expert Handbook for Planning, Design and Installation. Routledge, 2012.

[4] H. Mousazadeh, A. Keyhani, A. Javadi, H. Mobli, K. Abrinia, and A. Sharifi, "A review of principle and suntracking methods for maximizing solar systems output," Renewable and Sustainable Energy Reviews, vol. 13, no. 8. Pergamon, pp. 1800-1818, 01-Oct-2009.

[5] R. K. Kharb, S. L. Shimi, S. Chatterji, and M. F. Ansari, "Modeling of solar PV module and maximum power point tracking using ANFIS," Renewable and Sustainable Energy Reviews, vol. 33. Elsevier Ltd, pp. 602-612, 01-May-2014.

[6] B. K. Hammad, R. H. Fouad, M. S. Ashhab, S. D. Nijmeh, M. Mohsen, and A. Tamimi, "Adaptive control of solar tracking system," IET Science, Measurement and Technology, vol. 8, no. 6, pp. 426-431, Nov. 2014.

[7] S. Zhang, T. Wang, C. Li, J. Zhang, and Y. Wang, "Maximum power point tracking control of solar power generation systems based on type-2 fuzzy logic," in Proceedings of the World Congress on Intelligent Control and Automation (WCICA), 2016, vol. 2016September, pp. 770-774.

[8] C.-H. Huang, H.-Y. Pan, and K.-C. Lin, "Development of Intelligent Fuzzy Controller for a Two-Axis Solar Tracking System," Applied Sciences, vol. 6, no. 5, p. 130, May 2016.

[9] J.-M. Wang and C.-L. Lu, "Design and Implementation of a Sun Tracker with a Dual-Axis Single Motor for an Optical Sensor-Based Photovoltaic System," Sensors, vol. 13, no. 3, pp. 3157-3168, Mar. 2013.

[10] R. A. Muhammad E. H. Chowdhury, Amith Khandakar, Belayat Hossain, "A Low-Cost Closed-Loop Solar Tracking System Based on the Sun Position Algorithm," Journal of Sensors, vol. 2019, p. 11, 2019.

[11] Y. M. Safan, S. Shaaban, and M. I. Abu El-Sebah, "Performance evaluation of a multi-degree of freedom hybrid controlled dual axis solar tracking system," Solar Energy, vol. 170, pp. 576-585, Aug. 2018.

[12] B. J. Huang, Y. C. Huang, G. Y. Chen, P. C. Hsu, and K. Li, "Improving solar PV system efficiency using one-axis 3-position sun tracking," in Energy Procedia, 2013, vol. 33, pp. 280-287.

[13] G. M. Tina, S. Gagliano, G. Graditi, and A. Merola, "Experimental validation of a probabilistic model for estimating the double axis PV tracking energy production," Applied Energy, vol. 97, pp. 990-998, Sep. 2012.

[14] R. Eke and A. Senturk, "Performance comparison of a double-axis sun tracking versus fixed PV system," Solar Energy, vol. 86, no. 9, pp. 2665-2672, Sep. 2012.
[15] Y. Rambhowan and V. Oree, "Improving the dual-axis solar tracking system efficiency via drive power consumption optimization," Applied Solar Energy (English translation of Geliotekhnika), vol. 50, no. 2, pp. 74-80, Aug. 2014.

[16] J. G. W. Ramón Pallás-Areny, Sensors and Signal Conditioning. John Wiley \& Sons, 2012.

[17] S. J. Azhari and H. Kaabi, "AZKA cell, the currentmode alternative of Wheatstone bridge," IEEE Transactions on Circuits and Systems I: Fundamental Theory and Applications, vol. 47, no. 9, pp. 1277-1284, Sep. 2000.

[18] J. Zheng Li, CAD, 3D Modeling, Engineering Analysis, and Prototype Experimentation. Springer International Publishing, 2015.

[19] C. Y. Chen, X. Lin, S. T. Shih, C. M. Hsu, and C. Y. Liu, "Mechanism design and analysis for solar tracking system with 500W power output," in Lecture Notes in Electrical Engineering, 2014, vol. 293, pp. 195-204.

[20] W. Nsengiyumva, S. G. Chen, L. Hu, and X. Chen, "Recent advancements and challenges in Solar Tracking Systems (STS): A review," Renewable and Sustainable Energy Reviews, vol. 81. Elsevier Ltd, pp. 250-279, 01-Jan-2018.

[21] M. Abdollahpour, M. R. Golzarian, A. Rohani, and H. Abootorabi Zarchi, "Development of a machine vision dual-axis solar tracking system," Solar Energy, vol. 169, pp. 136-143, Jul. 2018.

[22] N. AL-Rousan, N. A. M. Isa, and M. K. M. Desa, "Advances in solar photovoltaic tracking systems: A review," Renewable and Sustainable Energy Reviews, vol. 82. Elsevier Ltd, pp. 2548-2569, 01-Feb-2018.

[23] I. Stamatescu, I. Făgărăşan, G. Stamatescu, N. Arghira, and S. S. Iliescu, "Design and implementation of a solar-tracking algorithm," in Procedia Engineering, 2014, vol. 69, pp. 500-507.

[24] J. K. Tharamuttam and A. K. Ng, "Design and Development of an Automatic Solar Tracker," in Energy Procedia, 2017, vol. 143, pp. 629-634.

[25] L.-M. Lelutiu, C.-M. Lungoci, M.-D. Calin, and M. Cirstea, "A power efficient mobile solar tracking system," 2017, pp. 561-566.

[26] P. R. Nagarajan, B. George, and V. J. Kumar, "A Linearizing Digitizer for Wheatstone Bridge Based Signal Conditioning of Resistive Sensors," IEEE Sensors Journal, vol. 17, no. 6, pp. 1696-1705, Mar. 2017.

[27] E. Alnasser, "A novel fully analog null instrument for resistive Wheatstone bridge with a single resistive sensor," IEEE Sensors Journal, vol. 18, no. 2, pp. 635640, Jan. 2018.

[28] A. el Hammoumi, S. Motahhir, A. Chalh, A. el Ghzizal, and A. Derouich, "Low-cost virtual instrumentation of PV panel characteristics using Excel and Arduino in comparison with traditional instrumentation," Renewables: Wind, Water, and Solar, vol. 5, no. 1, pp. 1-16, Dec. 2018. 